\title{
Talking about a nanny nation: investigating the rhetoric framing public health debates in Australian news media
}

\author{
Josephine Y Chau a,b,d, James Kite ${ }^{b}$, Rimante Ronto ${ }^{a}$, Alexandra Bhattia \\ and Catriona Bonfigliolic
}

a Department of Health Systems and Populations, Macquarie University, Sydney, NSW, Australia

b Prevention Research Collaboration, Sydney School of Public Health and Charles Perkins Centre, University of Sydney, NSW, Australia

c Faculty of Arts and Social Sciences, UTS, Sydney, NSW, Australia

${ }^{d}$ Corresponding author: josephine.chau@mq.edu.au

\section{Article history}

Publication date: September 2019

Citation: Chau JY, Kite J, Ronto R,

Bhatti A, Bonfiglioli C. Talking about a nanny nation: investigating the rhetoric framing public health debates in Australian news media. Public Health Res Pract. 2019;29(3):e2931922.

https://doi.org/10.17061/phrp2931922

\section{Key points}

- 'Nanny state' rhetoric is commonly used in Australian news media to portray negative views about public health regulation

- News Corp Australia, which holds a dominant position in the Australian news media, was the major propagator of nanny state rhetoric in articles about public health issues published in Australian newspapers

- Direct challenges to nanny state rhetoric in Australian news media are relatively scarce and strategies to increase the representation of such challenges in public discourse are needed

\section{Abstract}

Objectives and importance of study: News media portrayal of public health issues influences public opinion, policy action and decision making. This study aimed to analyse the use of 'nanny state' frames in Australian news media coverage; identify the stakeholders invoking this frame; determine which public health-related policies attract such framing; and investigate whether 'nanny state' framing is directly challenged in news coverage.

Study type: A qualitative framing analysis.

Methods: Articles featuring the term 'nanny state' that were published in Australian print newspapers during matched periods between March and September in 2017 and 2018 were sourced through Factiva, coded and analysed for content and 'nanny state' framing. Content analysis was used to identify any public health-related issues that the terminology nanny state was applied to, and who was portrayed as imposing the nanny state. Frame analysis was used to analyse what meanings are co-presented with the phrase nanny state.

Results: Out of 81 print newspaper articles that included the term 'nanny state', $19 \%$ linked the term to restricting personal choice or creating dissatisfaction with too many health-related rules and regulations broadly, across a range of issues, including: bike helmets, e-cigarettes, firearm restrictions, seatbelts, pool fences and smoking bans. The next most frequent links were to regulations on alcohol (17\%), road safety (14\%), obesity-related issues (7\%) and tobacco control (6\%). Of the 81 articles, $53 \%$ appeared in news publications owned by News Corporation Australia, 20\% in Fairfax Media (Nine Entertainment) publications, 17\% in Daily Mail and General Trust and $10 \%$ in publications owned by other organisations. Governments were the entity most frequently framed as imposing the nanny state. Most nanny state framings (73\%) were negative towards public health controls and focused on policies and regulations. Nanny state was portrayed as an assault on freedom 
and choice (14\%) and used to attack proponents of nanny state controls (11\%), while few articles framed the nanny state $(7 \%)$ in a favourable light.

Conclusions: 'Nanny state' is a rhetorical device commonly used in Australian news media that may contribute to discrediting of the regulation of a range of health-related issues. News Corp publications are a major propagator of nanny state rhetoric in Australian newspaper media. Public health advocates are not commonly represented within nanny state debates within the news media.

\section{Introduction}

New regulations intended to save lives or promote health often meet resistance from certain stakeholders who anticipate a threat to their revenue or their free choice. From issues such as seatbelts to tobacco plain packaging, arguments for freedom of choice have been raised, at least until researchers can present the evidence of the savings to life, limb and the public purse that such measures yield. ${ }^{1}$

News media coverage of health issues demonstrably influences public opinion, policy action and individual behaviour. ${ }^{2}$ It shapes understandings by setting the agenda ${ }^{3,4}$, selecting sources ${ }^{5-7}$, and framing issues, events and people. ${ }^{8}$ The strategic communication resources deployed to resist, reject, delay and dilute public health regulation are impressive and often successful, at least in the short term. . $^{910}$ The contest over the framing of public health regulation is often informed by the tobacco industry 'playbook'11, which outlines key strategies used by the tobacco industry to oppose regulation, such as emphasising individual responsibility and casting doubt on scientific findings linking products to disease and death. ${ }^{12}$ Industries tend to favour individual responsibility framing of health 'choices' and 'lifestyles' because it puts the onus on the individual to act responsibly and resist temptation. It also diverts attention from industry responsibility and policy choices that are designed to make the environment in which people make these 'choices' more health-promoting.

One powerful rhetorical device found in news media framing contests is that of 'nanny state', which is used to claim individuals' rights and free choice are threatened by paternalistic government policies. ${ }^{1,13,14}$ Among the most striking examples of nanny state framing was the Center for Consumer Freedom's full-page advertisement in the New York Times in 2012 attacking then New York City Mayor Michael Bloomberg's attempt to limit cup size on sugary drinks by depicting him as a matronly nanny looming over New York. ${ }^{15}$ The message of this advertisement was clear: Bloomberg is overbearing and treats New Yorkers as if they were children who need a nanny to tell them how to behave. As Wiley et al. note, 'nanny state' is a "slur" and commentators at the time were quick to tell Bloomberg it was none of his business if New Yorkers wished to drink sugary soda from supersized cups. ${ }^{1}$

Constraints on liberty are supported by law where the goal is to address profound health challenges, but public health advocates' efforts to address primordial causes of chronic ill health often conflict with the interests of commercial stakeholders whose products contribute to public health problems. ${ }^{1}$ The nanny state slur, Wiley et al. argue, is "a powerful framing device" that prompts people to think of the "state treating adults like children", restricting choice, killing fun and shutting down intelligent debate. ${ }^{1}$ It also deflects attention from the drivers of ill health towards government "overreach". Invoking this frame invites people to ask why their freedom should be restricted to protect people who are perceived as being unhealthy because of their own actions. Indeed, these have been identified in online news comments opposing plain packaging of tobacco products ${ }^{13}$ and in newspaper coverage of the debate on restrictions on food advertising to children. ${ }^{16}$

Daube and colleagues identify the "most virulent opponents of governmental action to protect our heath" as companies that spend billions on promotion and lobbying to influence "adults and children to smoke, drink and eat junk foods". ${ }^{17}$ Corporations in the business of selling alcohol and tobacco have also used nanny state rhetoric to attack government health policies since the 1990s. ${ }^{17}$ They drew on the 1965 coining of the phrase by a British health minister and smoker, Iain Macleod, and its perpetuation by smoking advocate Auberon Waugh. ${ }^{17}$

This study aims to: 1) investigate the deployment of nanny state frames in recent Australian news media coverage to identify the key players invoking this frame; 2) discover which public health-related policies currently attract such framing; 3) identify the range of concepts invoked by nanny state framing; and 4) investigate whether news coverage carries direct challenges to nanny state rhetoric.

\section{Methods}

\section{Data collection}

We searched the Factiva global news database for news articles published in Australia within two matched 6-month periods: 1 March-30 September in 2017 and in 2018 (Syntax: "Nanny state"/F100/ and re-austr; date of search: 11 October 2018; print and online articles were included, with duplicates removed). This sampling frame was chosen to avoid the slower summer news cycle and to account for the date the search was executed. Relevant news articles were those which mentioned 'nanny state' in the headline or first three paragraphs. 


\section{Article coding}

We used a coding protocol based on previous studies ${ }^{18-20}$ to record key information from each newspaper article (Table 1).

Four members of the research team independently extracted content and coded $25 \%$ of the articles each following the protocol. The authors then cross-checked the data from another researcher in pairs, with any disagreements in extraction and coding resolved by discussion.

Coding protocol items 1-8 (Table 1) had 100\% agreement between researchers on all items, except for errors regarding newspaper name (5/81 articles), article headline (8/81 articles), article byline (1/81 articles) and section of the publication (1/81 articles). These errors were resolved, and for the other coding items, which were more qualitative in nature, discrepancies were resolved through discussion.

\section{Framing analysis}

All sentences which included the phrase 'nanny state' were captured. We coded the first framing of nanny state by analysing words closest to the phrase. Some sentences contained multiple frames, and we reached saturation in the coding of the first fames. Coding was conducted by one researcher and allocation of framings to groups was discussed and confirmed by three other researchers.

\section{Results}

The search strategy generated 150 newspaper articles ( $n=68$ in 2017, $n=82$ in 2018); 69 were excluded, yielding a final sample of 81 news articles for analysis ( $n=43$ in 2017, $n=38$ in 2018). The main reasons for exclusions were because articles were: letters, reader comments or vox populi $(n=22)$; media releases $(n=4)$;

Table 1. Coding protocol for news articles featuring the term nanny state

\begin{tabular}{|c|c|}
\hline Item & Field name (description) \\
\hline 1 & Item ID number \\
\hline 2 & Publication date \\
\hline 3 & Source \\
\hline 4 & Page number \\
\hline 5 & Byline \\
\hline 6 & Article headline \\
\hline 7 & Article word count \\
\hline 8 & Section of publication \\
\hline 9 & $\begin{array}{l}\text { Main topic of first paragraph } \\
\text { (What is the issue being reported/ discussed? What is the article about?) }\end{array}$ \\
\hline 10 & $\begin{array}{l}\text { News angle } \\
\text { (What aspect of the issue/topic attracted the journalist's attention?) }\end{array}$ \\
\hline 11 & $\begin{array}{l}\text { Who or what is identified as imposing (or about to impose) a nanny state or a nanny state regulation? } \\
\text { (E.g., government, council, other authority, food or health organisation) }\end{array}$ \\
\hline 12 & Other individuals or groups mentioned in the article (if any) \\
\hline 13 & $\begin{array}{l}\text { Who is using the term nanny state? } \\
\text { (This could be the journalist, other type of article author, a directly quoted source, or attributed to a source) }\end{array}$ \\
\hline 14 & $\begin{array}{l}\text { What issue is nanny state language applied to? } \\
\text { (E.g. pokie machines, e-cigarettes, sugar tax, lockout laws, vaccination, racism, speed limits, pool fences, } \\
\text { seatbelts, bicycle helmets) }\end{array}$ \\
\hline 15 & All sentences including the phrase nanny state for frame analysis \\
\hline 16 & $\begin{array}{l}\text { Any sentence using language of 'choice', 'freedom', 'individual responsibility', 'political correctness' but not } \\
\text { including the phrase 'nanny state' }\end{array}$ \\
\hline 17 & What language is used to defend and support pro public health regulation/policies/restrictions? \\
\hline 18 & Who is portrayed as defending public health-promoting regulation? \\
\hline 19 & $\begin{array}{l}\text { Anything else of interest? } \\
\text { (Other language used to defend public health or resist regulation; other text of interest) }\end{array}$ \\
\hline
\end{tabular}


or articles not related to public health. The final sample included: news stories $(n=55)$, comment or opinion articles $(n=14)$, editorials $(n=2)$, articles in unspecified sections $(n=6)$ and miscellaneous sections e.g., business, lifestyle $(n=4)$.

These 81 newspaper articles were published in 36 unique news publications (see Supplementary Table 1, available from: researchers.mq.edu.au/en/ publications/talking-about-a-nanny-nation-investigatingthe-rhetoric-framing-p): 51\% were owned wholly or with a majority share by News Corp Australia, 11\% by Fairfax Media, $11 \%$ by Nine Entertainment Co., $17 \%$ by Daily Mail and General Trust, and $10 \%$ by other organisations (e.g., Seven West Media, Australian Broadcasting Corporation).

\section{To what issues was nanny state language applied?}

Out of 81 newspaper articles, the largest group were articles that cited a broad range of public health measures, focusing on restrictions on personal choice and/or dissatisfaction with too many rules and regulations in general (19\%) (see Table 2). The issues mentioned in these articles included bike helmets, e-cigarettes, firearms restrictions, seatbelts, pool fences, and smoking bans. Regulations on alcohol and road safety were the next most frequently identified issues to which nanny state language was applied, accounting for $17 \%$ and $14 \%$ of newspaper articles, respectively. Obesity-related issues accounted for 10 articles, $7 \%$ of articles dealt with taxation or regulation of sugary drinks and foods, and $5 \%$ concerned childhood obesity. Only $6 \%$ of articles focused on tobacco regulation.

\section{Who was using the term 'nanny state'?}

The majority of 'nanny state' mentions were made by the article authors, columnists or journalists (52/83 mentions, $63 \%$ ), and politicians accounted for $19 \%$ of the times 'nanny state' was used, e.g., Aaron Stonehouse (Member of Parliament, West Australian Government, $n=5$ ); David Leyonhjelm (then Senator, Australian Parliament, $n=3$ ). Spokepersons for peak bodies and stakeholder agencies accounted for 4\% (3/83 mentions) and only one attribution was from a health-related body (i.e., Freestyle Cyclists regarding bike helmet law reforms). Other 'nanny state' mentions were made by community members (2/83 mentions, $2 \%$ ) unattributed quotes (7/83 mentions, 8\%).

Table 2. What issue was nanny state language being applied to in newspaper articles? (March-September, 2017 and 2018)

\begin{tabular}{|c|c|c|c|}
\hline Issue of concern & $N$ & $\%$ & Sub-issue $(n)$ \\
\hline $\begin{array}{l}\text { Various measures that restrict } \\
\text { personal choice; too many rules and } \\
\text { regulations in general }\end{array}$ & 15 & 19 & $\begin{array}{l}\text { Article names range of issues such as bike helmets, e-cigarettes, } \\
\text { firearm laws, seatbelts, pool fences, smoking bans, regulations on food } \\
\text { and alcohol }\end{array}$ \\
\hline Alcohol & 14 & 17 & $\begin{array}{l}\text { Restrict sale and/or consumption (9); ID laws for bar entry (2); responsible } \\
\text { drinking (1); lockout laws (1); small bar regulation (1) }\end{array}$ \\
\hline Road safety & 11 & 14 & $\begin{array}{l}\text { For all users/in general (3); for motorcycles (1); speed limits (4); } \\
\text { compulsory bike helmets (3) }\end{array}$ \\
\hline Tax or regulation of sugary products & 6 & 7 & $\begin{array}{l}\text { Tax on sugary drinks (3); regulate sales of sugary drinks (2); sugar tax in } \\
\text { general (1) }\end{array}$ \\
\hline Tobacco control & 5 & 6 & $\begin{array}{l}\text { Smoking bans in apartments (1), in general (1), in public spaces (1); legal } \\
\text { smoking age (1); e-cigarettes (1) }\end{array}$ \\
\hline Gender equity & 5 & 6 & Inclusiveness (4); pay gap (1) \\
\hline Obesity - childhood & 4 & 5 & $\begin{array}{l}\text { General (1); proposal to weigh primary school children routinely (1); } \\
\text { unhealthy foods in schools (1); plain packaging for cereals (1) }\end{array}$ \\
\hline Gaming, gambling & 2 & 2 & No sub-issue \\
\hline Environmental sustainability & 2 & 2 & Sustainable eating (1); takeaway coffee cups (1) \\
\hline Firearms regulations & 2 & 2 & No sub-issue \\
\hline Fireworks regulations & 2 & 2 & No sub-issue \\
\hline Other & 13 & 16 & $\begin{array}{l}\text { Food safety (1); parking laws (1); safe play for kids (1); noise levels (1); } \\
\text { workplace harassment/safety (1); airspace safety/drones (1); safety \& } \\
\text { terrorism (1); marriage equality (1); safe schools program (1); live music } \\
\text { (1); hunting laws (1); dog poop laws (1); knife sales (1) }\end{array}$ \\
\hline
\end{tabular}




\section{Who was portrayed as responsible for imposing the nanny state?}

Of the 88 times that articles portrayed an agent as being responsible for imposing the nanny state, 49 named governments and six cited generic authorities as being responsible (see Supplementary Table 2, available from: researchers.mq.edu.au/en/publications/talking-about-ananny-nation-investigating-the-rhetoric-framing-p). Of these, $49 \%$ referred to state governments, $31 \%$ referred to local governments (e.g., councils), 14\% referred to government in general, and $6 \%$ referred to the Federal Government.

Non-government organisations (NGOs) and peak body groups were also cited as being responsible for imposing the nanny state $(n=11)$. These were all health-related agencies, such as the Obesity Policy Coalition, Cancer Council, World Health Organization, and Australian Health Promotion Association. Other entities seen to be imposing the nanny state included police $(n=5)$, schools or universities $(n=5)$, political parties $(n=3)$, campaigners and advocates $(n=4)$, workplaces $(n=3)$, safety regulators $(n=1)$, and social media $(n=1)$.

\section{How has the nanny state been framed?}

We identified 130 sentences which included the phrase nanny state across the 81 articles. These sentences were coded for frames which linked nanny state to other concepts. We identified 118 first framings which could be grouped and 12 others which could not be grouped (see Supplementary Table 3, available from: researchers.mq.edu.au/en/publications/talking-about-ananny-nation-investigating-the-rhetoric-framing-p). In the majority of cases ( $n=95)$, use of the term nanny state focused on health policies and regulations and was negative about such regulation. The nanny state was framed as an assault on freedom and choice $(n=18)$ which is an uninvited and unwanted invasion of our private lives $(n=8)$. Framings suggested that the nanny state is here $(n=11)$; growing $(n=7)$; out of control ( $n=8)$; and a kind of madness $(n=8)$. Other suggestions were that the nanny state treats us like stupid children $(n=4)$ and is akin to killjoy wowserism $(n=4)$. Other negative framing around the nanny state suggested: 'We' just don't like it $(n=7)$; it's a bad look $(n=4)$; and some news actors emphasised that 'we' don't have a nanny state here $(n=3)$ or 'we' are fighting the nanny state and beating it back $(n=13)$.

More than one in 10 framings $(n=14)$ was an attack on proponents of nanny state controls, describing them in a variety of ways including "Orwellian", "control freaks" and Green-linked "activists".

\section{Rare support}

Framings that might be interpreted as pro nanny state were rare $(n=9)$ : five items identified the use of nanny state labels as a cheap shot $(n=5)$; politicians are called out for using nanny state as flak against regulators $(n=3)$, and one item conceded that proponents of the nanny state laws were pro-health.

\section{Discussion}

The news media play a role in keeping issues in the public consciousness and on the political agenda. Over two matched periods in 2017 and 2018, we found 81 newspaper articles mentioning the nanny state in reporting and commentary on a range of public healthrelevant issues. One in five of these nanny state articles were personal opinion columns that criticised and expressed dissatisfaction with a multitude of issues deemed by the writers to be over-regulated and restrictive of personal choice.

Furthermore, our findings show that a majority of the nanny state articles were published by News Corp. This is unsurprising, given the dominance of New Corp in the Australian news media landscape ${ }^{21}$ and the company's promotion of free market ideology and opposition to 'political correctness'. 22

This study's observation of a tendency for governments to be criticised for imposing the nanny state in newspaper articles appears somewhat inconsistent with perceptions of lay community members. A national survey found $46 \%$ of respondents felt the government had a "large or very large" role in maintaining people's health and $80 \%$ "agreed or strongly agreed" that "sometimes the government needs to make laws that keep people from harming themselves", even though 90\% endorsed personal responsibility. ${ }^{23}$ This suggests that government policies and interventions on public health issues are generally viewed positively by community members rather than as unwanted impositions on personal liberties, despite the claims made by those invoking the nanny state rhetoric. Other research indicates community support for public health interventions depends on the nature of the intervention and the problem being addressed. ${ }^{24,25}$ For example, Diepeveen et al. ${ }^{24}$ found the most acceptable government interventions for healthrelated behaviour change were those perceived as least intrusive (e.g., food labelling vs. change in pricing) and those targeting the behaviours of other people. Yet, perceptions of individual risk and personal agency to benefit from government interventions remain a crucial factor in intervention effectiveness and equity. ${ }^{24}$

The results of this study suggest that proponents of new policies and regulations rarely directly challenge the use of nanny state language. If counter arguments using nanny state framing were made, they were not given sufficient prominence in newspaper coverage to appear in the sample (search captured articles using nanny state in headline/first three paragraphs). It is possible public health proponents avoided using nanny state language because it is seen as a slur which undermines healthpromoting policy. News media provides a platform for anti-nanny-state commentators through opinion pieces, 
which are traditionally used for single-voice arguments with little or no counter-arguments or alternative voices presented. ${ }^{26}$ The failure to directly challenge nanny state framing served to reinforce the nanny state frame as a rhetorical weapon of choice for opponents.

The qualitative framing analysis mapped concepts linked to the phrase nanny state thus providing insight into the constellation of meanings available in the primed reader's mind. These pre-formed anti-regulation schemas may thus be easily evoked when the phrase is used in isolation. The dominant frame is that the nanny state destroys freedom; an appeal to a value that sensible people would naturally support. ${ }^{23,27}$ In this sample, the nanny state is portrayed as mad, out of control and in need of being curtailed. The findings can help public health advocates and researchers recognise when such free-choice rhetoric is being deployed to delay, defer or block health measures intended to reduce death and disease. However, people who advocate for public health regulation expose themselves to being framed as Orwellian control freaks.

So how can public health advocates neutralise nanny state rhetoric? Public health researchers have called for more active and nuanced discussions of new public health measures and deliberate efforts to counter nanny state claims and de-emphasise individual rights. ${ }^{23,28,29}$ Strategies to counter nanny state arguments include: directly challenging nanny state rhetoric; highlighting the corporate and economic vested interests of proindustry speakers ${ }^{28,30}$, explaining different ways that personal freedoms can manifest in a pluralistic society ${ }^{29}$; humanising the debate about prevention policies by presenting personal stories of regret from previous opponents of new laws ${ }^{28}$; and discussing the various implications and consequences of new measures to facilitate a more complete assessment of issues by community members. ${ }^{23}$ In Australian community engagement work, Grunseit et al. ${ }^{23}$ observed various perceptions of the government's role in preventing ill health: as an investor in population health; a leader in promoting salutogenic behaviours; and a partner in supporting individual good health. These may be useful frames to use for communicating and garnering support for future government health interventions, at least in the Australian context.

\section{Strengths and limitations}

One strength of this study was the use of the Factiva electronic news database to collect data about the sample of news articles that mention nanny state in Australia. We selected all Australian outlets, resulting in a comprehensive collection of articles for analysis. However, it is a limitation of this study that we only searched for direct mentions of the term nanny state in the top of the articles. This means that articles discussing new or proposed public health policies and initiatives that did not explicitly use the term nanny state were not captured by our sampling strategy. We did not detect direct challenges to nanny state rhetoric which may have appeared towards the end of articles not captured. Nonetheless, our aim was to investigate use of 'nanny state' specifically and so this search strategy was appropriate. We also recognise that different audiences may de-code framings in a variety of ways; for example, conservative readers may favour a small government with low taxes, minimal control and maximum personal 'freedom', while public health professionals may read the phrase nanny state as a neoliberal catchphrase that is used to counter calls for increased government regulation. Statements lacking the nanny state phrase but supportive of public health regulation were present in the sample but were not the focus of this analysis, which aimed to detect meanings linked to 'nanny state' to enhance our understanding of the rhetorical power of the phrase even when used in isolation.

\section{Conclusions}

This study demonstrates the ways in which newspaper media have presented nanny state rhetoric in the discourse about laws and regulations impacting public health. It quantifies the sources of Australian newspaper articles using nanny state rhetoric, pinpointing News Corp publications as major propagators of this rhetoric in the study period. Based on this investigation, it appears news media-hosted nanny state debates are dominated by opponents of new public health initiatives.

Our study focused on overt use of nanny state language detecting a relative lack of direct challenges to nanny state rhetoric. Nanny state rhetoric carries powerful meanings such as an assault on choice, freedom and fun, concepts which may undermine public health professionals' efforts to build and sustain public support for health-promoting regulation. The lack of public health professionals using the phrase suggests they may be avoiding the nanny state playbook and instead refocusing the narrative on advantages of regulation. Nonetheless, public health advocates will continue to be challenged by news media dominated by nanny state arguments, along with the disproportionately vast resources of industry players with vested interests in resisting regulation of their products.

Future directions for public health researchers to consider include investigating how public health advocates have attempted to counter nanny state rhetoric, and whether they have been effective in garnering media attention.

\section{Peer review and provenance}

Externally peer reviewed, invited. 


\section{Competing interests}

None declared.

\section{Author contributions}

$\mathrm{JC}$ and CB conceived of the paper and designed the methods. JC searched for articles. JC, JK, RR, AB coded news articles for content. $\mathrm{CB}$ carried out the framing analysis with verification by JK, RR and $A B$. JC carried out the descriptive analysis. JC and CB drafted the manuscript. All authors contributed to interpretation of results and critically reviewed and revised the manuscript.

\section{References}

1. Wiley LF, Berman ML, Blanke D. Who's your nanny? choice, paternalism and public health in the age of personal responsibility. J Law Med Ethics. 2013;41:88-91.

2. Walsh-Childers K. Mass media and health: examining media impact on individuals and the health environment. New York, London: Routledge; 2016.

3. McCombs M, Shaw D. The agenda-setting function of mass media. Public Opin Quart. 1972;36(2):17687.

4. McCombs M, Valenzuela S. The agenda-setting theory. Cuadernos de Información. 2007;20:4450.

5. Phillips A. Journalists and their sources'. Journalism in context: practice and theory for the digital age. London, New York: Routledge, Taylor \& Francis Group; 2015. p. 40-59.

6. Carlson M. Dueling, dancing, or dominating? Journalists and their sources. Sociology Compass. 2009;3(4):526-42.

7. Couldry N. Why voice matters: culture and politics after neoliberalism. London: Sage Publications; 2010.

8. Entman RM. Framing: toward clarification of a fractured paradigm. J Commun. 1993;43(4):51-58.

9. Trotter L, Chapman S. Conclusions about exposure to ETS and health that will be unhelpful to us: how the tobacco industry attempted to delay and discredit the 1997 Australian National Health and Medical Research Council report on passive smoking. Tob Control. 2003;12(suppl 3):iii102-6.

10. Assunta M, Chapman S. A mire of highly subjective and ineffective voluntary guidelines: tobacco industry efforts to thwart tobacco control in Malaysia. Tob Control. 2004;13(suppl 2):ii43-50.

11. Chaloupka FJ. Lessons for obesity policy from the tobacco wars. In: Cawley J, editor. The Oxford handbook of the social science of obesity. Oxford, UK: Oxford University Press, USA; 2011. p. 620-38.

12. Brownell K, Warner K. The perils of ignoring history: Big Tobacco played dirty and millions died. How similar is Big Food? Milbank Q. 2009;87(1):259-94.
13. Freeman B. Tobacco plain packaging legislation: a content analysis of commentary posted on Australian online news. Tob Control. 2011;20(5):321-22.

14. Fogarty AS, Chapman S. Advocates, interest groups and Australian news coverage of alcohol advertising restrictions: content and framing analysis. BMC Public Health. 2012;12(1):727.

15. Dicker R. 'Nanny Bloomberg' ad in New York Times targets N.Y. Mayor's anti-soda crusade. Huffington Post; 2012 May 6 [cited 2019 Aug 20]. Available from: www. huffingtonpost.com.au/2012/06/04/nanny-bloomberg-adin-new_n_1568037.html

16. Udell T, Mehta K. When two sides go to war: newspaper reporting of 'television food advertising restrictions' as a solution to childhood obesity. Health Risk Soc. 2008;10(6):535-48.

17. Daube M, Stafford J, Bond L. No need for nanny. Tob Control. 2008;17(6):426-27.

18. Bonfiglioli C, Smith BJ, King LA, Chapman SF, Holding SJ. Choice and voice: obesity debates in television news. Med J Aust. 2007;187(8):442-45.

19. Bonfiglioli C, Hattersley L, King L. Australian print news media coverage of sweet, non alcoholic drinks sends mixed health messages. Aust NZ J Pub Health. 2011;35(4):325-30.

20. Chau JY, Bonfiglioli C, Zhong, Pedisic Z, Daley M, McGill B, Bauman A. Sitting ducks face chronic disease: an analysis of newspaper coverage of sedentary behaviour as a health issue in Australia 2000-2012. Health Promot J Aust. 2017;28(2):139-43.

21. Australian Communications and Media Authority. 'Media interests' snapshot. Canberra: Australian Government; 2019 [cited 2019 July 3]. Available from: www.acma.gov. au/theACMA/media-interests-snapshot

22. McKnight D. Rupert Murdoch's News Corporation: a media institution with a mission. Hist J Film Radio Telev. 2010;30(3):303-16.

23. Grunseit AC, Rowbotham S, Crane M, Indig D, Bauman AE, Wilson A. Nanny or canny? Community perceptions of government intervention for preventive health. Crit Public Health. 2018;2:1-6.

24. Diepeveen S, Ling T, Suhrcke M, Roland M, Marteau TM. Public acceptability of government intervention to change health-related behaviours: a systematic review and narrative synthesis. BMC Public Health. 2013;13(1):756.

25. Adams J, Mytton O, White M, Monsivais P. Why are some population interventions for diet and obesity more equitable and effective than others? The role of individual agency. PLOS Medicine. 2016;13(4):e1001990.

26. McKewon E. Talking points ammo: the use of neoliberal think tank fantasy themes to delegitimise scientific knowledge of climate change in Australian newspapers. Journalism Stud. 2012;13(2):277-97. 
27. Lundell H, Niederdeppe J, Clarke C. Public views about health causation, attributions of responsibility, and inequality. J Health Commun. 2013;18(9):1116-30.

28. Magnusson RS. Case studies in nanny state name-calling: what can we learn? Public Health. 2015;129(8):1074-82.
29. Carter SM, Entwistle VA, Little M. Relational conceptions of paternalism: a way to rebut nanny-state accusations and evaluate public health interventions. Public Health. 2015;129(8):1021-9.

30. Moore M, Yeatman H, Davey R. Which nanny - the state or industry? Wowsers, teetotallers and the fun police in public health advocacy. Public Health. 2015;129(8):1030-37.

\section{Copyright: (c) (1) (2)}

(C) 2019 Chau et al. This article is licensed under the Creative Commons Attribution-NonCommercial-ShareAlike 4.0 International Licence, which allows others to redistribute, adapt and share this work non-commercially provided they attribute the work and any adapted version of it is distributed under the same Creative Commons licence terms. See: www.creativecommons.org/licenses/by-nc-sa/4.0/ 